\title{
Is the choice of a farm's commercial market an indicator of agricultural intensity? Conventional and short food supply chains in periurban farming systems
}

\author{
Rosalia Filippini, ${ }^{1,2}$ Elisa Marraccini, ${ }^{3}$ Sylvie Lardon, ${ }^{2}$ Enrico Bonari ${ }^{1}$ \\ ${ }^{1}$ Institute of Life Sciences, Scuola Superiore Sant'Anna, Pisa, Italy; ${ }^{2}$ UMR 1273 Métafort, \\ INRA and AgroParisTech, Aubière, France; ${ }^{3}$ UP 2012-10-103 PICAR-T, Polytechnic Institute \\ La Salle Beauvais, France
}

\begin{abstract}
Short food supply chains (SFSCs) have been identified as an economic opportunity for agriculture under urban pressure, as well as drivers for more sustainable farming systems. However, few studies have focused on the intensity of periurban farms that participate in such SFSCs, compared with the performance of the other farms. In this paper, we examined the relationship between agricultural intensity and the market orientation in a representative sample of farms in the urban area of Pisa (Italy). We define agricultural intensity as the intensity of land use and its main drivers (e.g., farm management or the individual characteristics of farmers), and market orientation as the ratio of farm produce within conventional, short or mixed foodsupply chains. The results suggest that the market orientation of periurban farming systems is more correlated to the indicators of farm management and land use intensity than to the individual farmer's characteristics. This result provides the first evidence that market orientation is a driver of intensity, and that individual farmer's characteristics are not significantly different in the three groups of market orientation. These findings could be generalised to other urban areas and
\end{abstract}

Correspondence: Rosalia Filippini, Institute of Life Sciences, Scuola Superiore Sant'Anna, p.zza Martiri della Libertà 33, 56127 Pisa, Italy.

E-mail: rosalia.filippini@gmail.com

Key words: Periurban agriculture; food supply chains; farm management; Tuscany.

Acknowledgements: the authors acknowledge ANR funding via the DAUME project n ${ }^{\circ}$ ANR-2010-STRA-007-01 and the Scuola Superiore Sant'Anna for RF $\mathrm{PhD}$ grant.

Conference presentation: SIA XLIII Congress, Pisa, 2014.

Received for publication: 30 January 2015.

Revision received: 13 October 2015.

Accepted for publication: 24 October 2015.

(C) Copyright R. Filippini et al., 2016

Licensee PAGEPress, Italy

Italian Journal of Agronomy 2016; 11:653

doi:10.4081/ija.2016.653

This article is distributed under the terms of the Creative Commons Attribution Noncommercial License (by-nc 4.0) which permits any noncommercial use, distribution, and reproduction in any medium, provided the original author(s) and source are credited. correlated with the main orientation of farming systems in order to support both the assessment of farming systems and the implementation of innovative urban food policies.

\section{Introduction}

The European Environmental Agency (EEA, 2010) has highlighted that periurban agricultural areas are affected by urbanisation in terms farmland loss and fragmentation. These dynamics are particularly pronounced in Mediterranean countries (Marraccini et al., 2015). Urbanisation affects not only ecosystem services (Foley, 2005; Zasada et al., 2011), but also the potential productivity of agricultural areas by impacting on farmers' choices and environmental resources (Agrawal et al., 2003; Akimowitz, 2012). These dynamics of urban growth are thus threatening agriculture in periurban areas. However, several studies have also pointed out how urbanisation has redesigned the economic relationships in these areas, offering new opportunities for agriculture (Soulard and Aubry, 2012).

More recently the function of periurban agriculture in terms of food production has been studied, linked to the opportunities offered by short food supply chains (SFSCs) (Paül and McKenzie, 2013). SFSCs are defined as innovative food chains characterised by a restored and more direct connection between producers and consumers (Renting $e t$ al., 2003). Especially in periurban areas, the adoption of SFSCs has been seen as an indicator of the farmer's adaptation to being in proximity to an urban area (Lamine and Perrot, 2008). It is generally stated within the literature on SFSCs that these farming systems are beneficial for the environment (Renting et al., 2003; Cleveland et al., 2014) and they are generally associated with more sustainable rural development (Sundkvist et al., 2005; Maréchal and Spanu, 2010; Forrssel and Lankoski, 2014). Although SFSCs could represent a real market opportunity for periurban farmers, and thus they could prevent agricultural abandonment in urban areas, periurban farming systems oriented to SFSCs have been often neglected by mainstream agronomic literature. Indeed, traditional approaches on SFSCs are more focused on how the relationships are established, and their social and economical benefits. A more in-depth study on the farming systems is thus necessary in order to properly assess their sustainability (Goodman, 2004; Simoncini, 2015).

The aim of this study is to carry out a preliminary study on the relationship between the market's orientation and the agricultural intensity of periurban farming systems. We define the agricultural intensity of farming systems as both the intensity of land use and its drivers, i.e., the farm structure, farm management, and the individual farmer's characteristics. We define market orientation according to Renting et al. (2003), i.e., as the conscious market destination either locally in 
SFSCs or in conventional food supply chains where the producer relies on traders, or producer's cooperatives.

The paper is organised as follows. In Materials and methods section we describe the methodology developed in terms of indicators, case study and statistical analysis. In Results section we discuss the main results obtained in the case study of the urban area of Pisa. Finally, we discuss our method and main results and draw conclusions on the agricultural intensity of periurban farming systems.

\section{Materials and methods}

\section{The urban area of Pisa (Italy): a representative area of Mediterranean urbanised coastal plains}

The case study is the urban area of Pisa, a medium-sized city in Tuscany (Italy). As already described by Filippini et al. (2014), this region has a surface of $500 \mathrm{~km}^{2}$ and consists of six municipalities located in the coastal plain of the Arno river and on the hilly area known as the Monte Pisano (917 $\mathrm{m}$ a.s.l). The area has a population density of almost 400 inhabitants per $\mathrm{km}^{2}$ and follows the European urban demographic trend for the last decade: a decrease in the city-centre inhabitants ( $-4 \%$ in the last decade) and a significant increase in the periur- ban areas ( $+8 \%$ in the last decade). Local farming systems are typically Mediterranean and oriented to cereal production, livestock, industrial crops or specialised crops such as horticultural or olive groves (Marraccini et al., 2013). The case study is representative of the transition of the main farming systems: a decrease in hectares of usable agricultural area (UAA) (-16\%) and above all in the number of farms particularly in more intensive productions such as horticultural and fruit groves $(-94 \%)$, while cereal and industrial crops farms has decreased less $(-50 \%)$.

The case study is also relevant considering the interest of local institutions in developing a food plan of the area, which included the contribution of local food supply to feed the inhabitants of the area (Di Iacovo et al., 2013).

\section{Data collection}

The analysis was based on 31 variables measured through 55 semistructured farm interviews. The interviews were carried out in 2013 and represented almost $10 \%$ of the total number of farms in the area according to the last agricultural census. We sampled the surveyed farms not for their market orientation but rather considering their dominant land use (e.g., industrial crops, cereals, fodder, olive groves and horticultural crops), the size of the farm according to the UAA and the distance of the farmstead from the main city centre. These three

Table 1. List of the selected indicators used in the analysis.

\begin{tabular}{|c|c|c|c|c|}
\hline Type of indicator & Indicator & Code & Content & Unit \\
\hline \multirow[t]{11}{*}{ Farm structure and land use } & Usable agricultural area & UAA & On farm surface used for arable and permanent crops & ha \\
\hline & Share of the UAA owned & SUAAp & Percentage of the UAA owned by the farms & $\%$ \\
\hline & Number of landowners & $\mathrm{Np}$ & Number of different landowners on the farmland & Value \\
\hline & Share of UAA in winter cereals & SUAAwc & Percentage of winter cereals in UAA & $\%$ \\
\hline & Share of UAA in horticultural crops & SUAAho & Percentage of horticultural crops in UAA & $\%$ \\
\hline & Share of UAA in olive groves & SUAAog & Percentage of olive groves in UAA & $\%$ \\
\hline & Share of UAA in fodder & SUAAf & Percentage of fodder in UAA & $\%$ \\
\hline & Number of farm blocks & Nblocks & Number of adjacent groups of fields belonging & Value \\
\hline & & & to the same farmer and managed in the same way & \\
\hline & Distance between blocks & Dblocks & Maximum distance of blocks between different on-farm blocks & $\mathrm{km}$ \\
\hline & Distance from the city & Durb & Distance of the farmstead from the main city centre & $\mathrm{km}$ \\
\hline \multirow[t]{10}{*}{ Farm management } & Livestock unit & UGBT & Number of livestock units on the farm & Value \\
\hline & Type of machinery & Equip & Main types of machinery available on the farm & Value \\
\hline & Share of full-time workers & Nftw & Share of full time workers out of the total workers of the farm & $\%$ \\
\hline & Number of seasonal workers & Nsw & Number of seasonal workers per farm & Value \\
\hline & Number of food chains & Nfc & $\begin{array}{l}\text { Number of different food chains of the farm } \\
\text { (on-farm direct selling, shops, cooperatives, etc.) }\end{array}$ & Value \\
\hline & Number of cultivated products & Nsp & Number of different crops cultivated on the farm & Value \\
\hline & Number of labels & Nlabel & Number of different labels on one or several farm produce & Value \\
\hline & Number of other activities & Nact & Number of different on-farm activities & Value \\
\hline & Innovation dynamics & DynInn & $\begin{array}{l}\text { Dynamics of innovation on the farm }(0=\text { decreasing, } \\
1=\text { stability, } 2=\text { increasing })\end{array}$ & $0 / 1 / 2$ \\
\hline & Organic production & Org & Presence of organic production ( $0=$ conventional or other, $1=$ organic) & $0 / 1$ \\
\hline \multirow[t]{5}{*}{ Land use intensity } & Irrigation & $\operatorname{Irr}$ & Presence of irrigation ( $0=$ rainfed, $1=$ irrigated $)$ & $0 / 1$ \\
\hline & Livestock intensity & LivDen & Number of livestock unit per hectare & Value/ha \\
\hline & Tree density & DTrees & Number of trees per hectare & Value/ha \\
\hline & Manure/organic fertiliser & OrgFert & $\begin{array}{l}\text { Application of manure or other organic fertilisers } \\
(0=\text { no manure, } 1=\text { use of manure })\end{array}$ & $0 / 1$ \\
\hline & Number of pesticide applications & Nphyto & Number of pesticide applications on the more intensive crops & Value \\
\hline \multirow[t]{6}{*}{ Individual farmer's characteristics } & Number of years & Nyears & On-farm work experience & Value \\
\hline & Type of education & Tedu & $\begin{array}{l}\text { Type of educational background }(0=\text { no; } 1=\text { basic no agri; } \\
2=\text { advanced no agri; } 3=\text { agri; } 4=\text { advanced agri })\end{array}$ & 0 to 4 \\
\hline & Age & Age & Age of the farmer or the main farmer manager $(0=<40 ; 1=40-65 ; 2=>65)$ & $0 / 1 / 2$ \\
\hline & Number of networks & Nnet & Number of networks the farmer belongs to & Value \\
\hline & Agricultural background & Agri & Agricultural background of family $(0=$ no, $1=y e s)$ & $0 / 1$ \\
\hline & Type of enterprise & Tjury & $\begin{array}{l}\text { Type of farm ( } 0=\text { family; } 1=\text { cooperative; } 2=\text { enterprise; } \\
3=\text { technical agricultural; } 4=0 \text { other })\end{array}$ & Value \\
\hline
\end{tabular}


criteria allowed us to select those farms more illustrative of the local farming systems and at the same time differently constrained by the proximity to the city.

The questionnaire was based on the main characteristics of the farm, the crop management, the marketing of the products, the farmer projects and the main advantages and disadvantages of being near an urban centre. For more details, see Filippini et al. (2014).

The sampled farms were thus classified in three groups, considering the marketing of the farm products declared by the farmers: conventional (CFC), if the farm produce is allotted totally to conventional food supply chains; short (SFC) it is devolved totally to short food supply chains, mixed (MFC) if it is devolved to both conventional and short food supply chains.

\section{Analysis of the relationships between agricultural intensity and the market orientation of farms}

The agricultural intensity was assessed with four groups of indicators without combining them with an overall score of intensity. A total of 31 indicators were calculated for each farm, referring to four items: the farm structure (e.g., farm size, land use); the farm management (e.g., crop management, livestock management, multifunctionality); the land use intensity (e.g., livestock density, irrigation) and the individual farmer characteristics (e.g., age, agricultural background). Indicators were identified by literature (Dumanski and Pieri, 2000; Herzog et al., 2006); thus they have been selected considering their capacity in discriminate between farms using analysis of the variation coefficient (cv) and excluding those indicators with a cv lower than 0.30 (little diversity).

Table 1 provides a list of the indicators used in the analysis, and the motivation for their adoption.

A descriptive analysis has been performed (data not shown) in order to characterise our farm sample. Afterwards, the relation between each indicator of agricultural intensity and the three market orientations identified was assessed using a Kruskal-Wallis test, since the indicators generally had a non-normal distribution (Kruskal and Wallis, 1953).

\section{Results}

\section{Characteristics of farms and localisation for the three market orientations}

Considerable differentiation was found in the number of farms belonging to each group: only $10 \%$ of the farms sell the total production in SFCs, versus $47 \%$ of farms that sell exclusively in CFCs. An interesting result was the huge percentage of farmers (43\%) that mix short and conventional food supply chains. We also found a difference in the type of farms belonging to each group. In fact, farmers that are exclusively in CFCs generally grow cereals and industrial crops (respectively $26 \%$ and $34 \%)$. On the other hand, horticulture seems to be more rep-

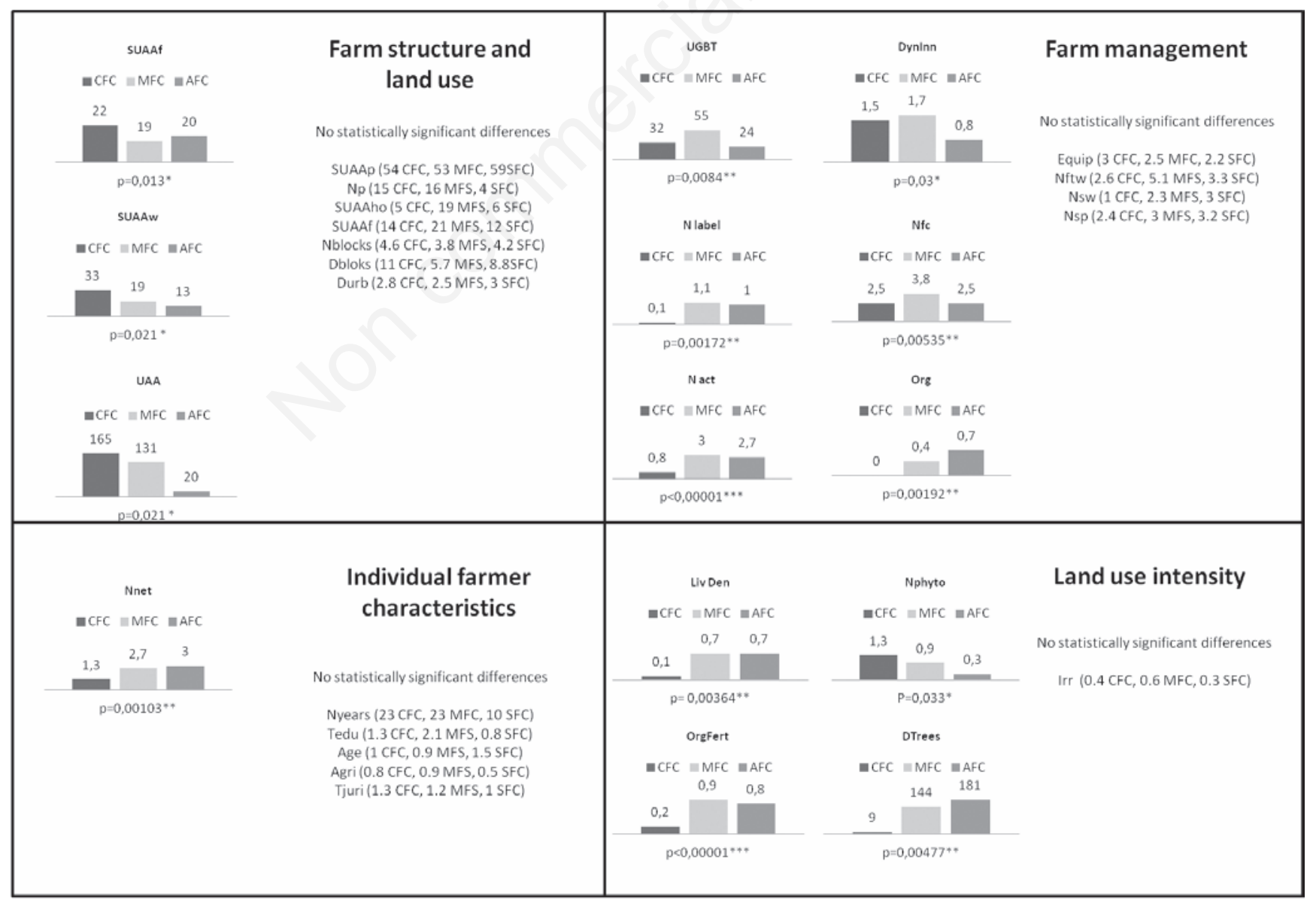

Figure 1. Main results of the statistical analysis (for each indicators' code see Table 1). 
resented by farmers selling in SFCs and MFCs, although in both these groups this represents only about $20 \%$. Both groups have a greater percentage of producers of fodder - livestock orientation and olive groves: $29 \%$ in MFCs and $40 \%$ in SFCs. The only difference between the two groups is that in the MFC group, there are producers of industrial and cereal crops (16\%), while no cereal or industrial crop farms participate exclusively in SFCs.

The distance from the urban area does not seem to affect the three groups and producing close to the urban city does not affect the market orientation of farms.

\section{Land use intensity and farm management provide sta- tistically significant differences in the market orienta- tion of farms}

Figure 1 shows the main results of the statistical analysis.

It is possible to observe two main results. The first result concerns the group of indicators with significant differences depending on the market orientation. We found that land use intensity (4 significant indicators out of 6) and farm management (6 indicators out of 10) were the agricultural intensity groups most related to market orientation. However, farm structure and individual farmers' characteristics were less related to market orientation (respectively 3 out of 10 , and 1 out of 6 ). This result is important because it is the first evidence that market orientation could be a driver of agricultural intensity. Farms exclusively in CFCs generally have higher values of intensity, but this is not the case for all the indicator values. Livestock density and tree density for olive groves have higher values for farms exclusively in alternative food chains, thus suggesting that even farms in SFCs can have an intensive farming practice or land use. However, since an overall score was not calculated, we were not able to predict which market orientation was more or less intensive. This opens up a new research area for the assessment of the agricultural intensity of periurban farming systems.

Moreover we demonstrated that in this case study, the farm structure or the individual farmer's characteristics are not significantly different in the three groups of market orientation, which in fact is more related to the type of farming system.

The second result concerns the differences in the indicator values within each market orientation group. We found very different dynamics unrelated to the indicator group. In fact, in some cases, there is a regular gradient between the indicator values within each group (e.g., the ratio of cereal surface within the UAA, which decreases from the CSC farms to the SFCs), or a similar value in two out of the three groups (e.g., the average number of multifunctional activities, which has almost the same value in MFCs and SFCs whereas it decreases for CFCs). Our interpretation is that this result may depend on the nature of the MFC, which was not completely defined in this work. In fact, MFC may be related to a different food chain for different farm product (e.g., cereals and milk or meat for livestock farms) or for a market diversification strategy for each kind of products (e.g., a market orientation in SFCs and CFCs for vegetables in horticultural farms). An in-depth analysis of MFCs is needed in order to understand their type and frequency within each farming system.

\section{Conclusions}

In this preliminary study, we have demonstrated that there is a relationship between market orientation and the agricultural intensity of periurban farming systems. Moreover we have shown that this relationship is more complex than what several scholars have claimed, promoting SFCs as tool for a less intensive farming in periurban areas: considering our results there is no evidence that a farming system in CFC is more intense than another oriented to SFC. This contribution leaves for further analysis to investigate the nature of this link. We suggest two possible ways to deep the analysis: firstly, to assess a single agricultural intensity index and secondly, to extend the statistical analysis using a multivariate model in order to consider other environmental and agricultural variables. We finally suggest that further agronomical research on periurban agriculture should be more focused on periurban farming systems, in order to assess their intensity, the services they provide, and their real contribution to local food policies.

\section{References}

Agrawal M, Singh B, Rajput M, Marshall F, Bell JN, 2003. Effect of air pollution on peri-urban agriculture: a case study. Environ. Pollut. 126:323-9.

Akimovitz M, 2012. Le changement structurel des exploitations agricoles périurbaines Le cas des grandes cultures dans le Lauragais midi-pyrénéen. Degree Diss. University of Toulouse, France.

Cleveland D, Carruth A, Mazaroli D, 2014. Operationalizing local food: goals, actions, and indicators for alternative food systems. Agric. Hum. Value. 32:281-97.

Dumanski J, Pieri C, 2000. Land quality indicators: research plan. Agric. Ecosyst. Environ. 81:93-102.

Di Iacovo F, Brunori G, Innocenti S, 2013. Le strategie urbane: il piano del cibo. Agriregionieuropa 32:9-16.

EEA (European Environment Agency), 2010. The European environment state and outlook. Land use. Available from: http://www. eea.europa.eu/soer/europe/land-use

Filippini R, Marraccini E, Lardon S, Bonari E, 2014. Assessing food production capacity of farms in periurban areas. Ital. J. Agron. 9:63-70.

Foley JA, 2005. Global consequences of land use. Science 309:570-4.

Forssell S, Lankoski L, 2014. The sustainability promise of alternative food networks: an examination through "alternative" characteristics. Agric. Hum. Values. 32:63-75.

Goodman D, 2004. Rural Europe redux? Reflections on alternative agrofood networks and paradigm change. Sociol. Rural. 44:3-16.

Herzog F, Steiner B, Bailey D, Baudry J, Billeter R, Bukácek R, De Blust G, De Cock R, Dirksen J, Dormann CF, 2006. Assessing the intensity of temperate European agriculture at the landscape scale. Eur. J. Agron. 24:165-81.

Kruskal WH, Wallis WA, 1953. Use of ranks in one-criterion variance analysis. J. Am. Stat. Assoc. 47:583-621.

Lamine C, Perrot N, 2008. Les AMAP: un nouveau pacte entre producteurs et consommateurs? Available from: http://www.souffledor.fr/ igc/fichier/SO/souffledor_bou/produit/EXTRAIT\%20les\%20AMAP\% 20introduction.pdf

Marraccini E, Debolini M, Moulery M, Abrantes P, Chéry J-P, Sanz Sanz E, Sabbatini T, Napoleone C, 2015. Common features and different trajectories of land cover changes in six Western Mediterranean urban regions. Appl. Geogr. 62:347-56.

Marraccini E, Lardon S, Loudiyi S, Giacché G, Bonari E, 2013. Durabilité de l'agriculture dans les territoires périurbains méditerranéens: enjeux et projets agriurbains dans la région de Pise (Toscane, Italie). Cahiers Agric. 22:517-25.

Maréchal G, Spanu A, 2010. Les circuits courts favorisent-ils l'adoption de pratiques agricoles plus respectueuses de l'environnement? Courrier Environ. INRA 59:33-46.

Paül V, McKenzie FH, 2013. Peri-urban farmland conservation and development of alternative food networks: Insights from a casestudy area in metropolitan Barcelona (Catalonia, Spain). Land Use 
Policy 30:94-105.

Renting H, Marsden TK, Banks J, 2003. Understanding alternative food networks: exploring the role of short food supply chains in rural development. Environ. Plan. A 35:393-411.

Simoncini R, 2015. Introducing territorial and historical contexts and critical thresholds in the analysis of conservation of agro-biodiversity by Alternative Food Networks, in Tuscany, Italy. Land Use Policy 42:355-66.
Soulard C, Aubry C, 2012. Quelle utilisation de l'espace en zones rurales et péri-urbaines? Agron. Environ. Soc. 2:88-101.

Sundkvist Å, Milestad R, Jansson A, 2005. On the importance of tightening feedback loops for sustainable development of food systems. Food Policy 30:224-39.

Zasada I, Fertner C, Piorr A, Nielsen TS, 2011. Peri-urbanisation and multifunctional adaptation of agriculture around Copenhagen. Geogr. Tidsskr.-Dan. J. Geogr. 111:59-72. 